\title{
Laboratory Model Study on the Pile-Forming Mechanisms and Bearing Deformation Characteristics of CFA Piles
}

\author{
Deliang Zhu $\mathbb{D}^{\mathbb{D}},{ }^{1,2,3}$ Yue Li $\mathbb{D}^{2,4}$ Lingwei Zheng $\mathbb{D}^{4,5}$ Pengfei Fang $\mathbb{D}^{4,5}$ and Xinyu Xie $\mathbb{i}^{2,4,6}$ \\ ${ }^{1}$ College of Civil Engineering \& Architecture, Wuyi University, Wuyishan 354300, China \\ ${ }^{2}$ Research Center of Coastal and Urban Geotechnical Engineering, Zhejiang University, Hangzhou 310058, China \\ ${ }^{3}$ Provincial Engineering Research Center of Prevention and Control of Geological Hazards of Mountainous \\ Region of Northern Fujian Province, Wuyishan 354300, China \\ ${ }^{4}$ NingboTech University, Ningbo 315100, China \\ ${ }^{5}$ Ningbo Research Institute, Zhejiang University, Ningbo 315100, China \\ ${ }^{6}$ Institute of Wenzhou, Zhejiang University, Wenzhou 325036, China
}

Correspondence should be addressed to Xinyu Xie; xiexinyu@zju.edu.cn

Received 12 August 2021; Revised 14 October 2021; Accepted 5 November 2021; Published 10 December 2021

Academic Editor: Jian Zhang

Copyright ( $\odot 2021$ Deliang Zhu et al. This is an open access article distributed under the Creative Commons Attribution License, which permits unrestricted use, distribution, and reproduction in any medium, provided the original work is properly cited.

To study the pile-forming mechanism and bearing deformation characteristics of continuous flight auger (CFA) piles, a series of procedures, including helical drilling, pulling up/grouting, and inserting cage/pile forming, were simulated in clay-sand doublelayer foundations by a homemade model drilling machine system in laboratory model tests. The effects of two different pileforming methods on the load transfer and bearing characteristics of the piles were investigated by performing a model test comparison of CFA piles and bored piles. The experimental results show that there exist a soil improvement effect around the pile and a diameter expansion effect during the drilling process and grouting process for the CFA pile, which can effectively improve the lateral friction resistance of the pile. Compared with the bored pile, the pile diameter in the middle of the CFA pile increased by $19 \%$, and the total lateral friction resistance of the CFA pile increased by $9.1 \%$ at a high load (1500 N). The comparative results of the model tests show that the bearing capacity of a single CFA pile increased by $50.0 \%$ and that the total settlement decreased by $40.5 \%$. The results of the in situ test piles show that the load-settlement curves of the two pile types are similar under low-medium loads and that the lateral friction resistance of the CFA pile under high loads is better developed, which is relatively consistent with the model test results.

\section{Introduction}

Continuous flight auger (CFA) piles, which are also known as augered cast-in-place (ACIP) or auger-cast piles, comprise a new construction method for pile foundations. Different from an ordinary drilling pile, CFA piles use a CFA to drill down to the design depth, and the dregs are sent upward to the ground through spiral blades. The concrete is pumped into the hollow center of the auger pipe through the pumping equipment, and the auger pipe is promoted to the ground surface while the concrete is pumped. The steel cage is inserted to finish the pile-forming process [1]. The common research methods of the bearing characteristics of pile foundations are field tests, numerical analyses, and model tests.

In terms of field tests, Bersan et al. [2], Polishchuk and Tarasov [3], Elsamee [4], and Liu et al. [5] conducted research on the bearing performances of CFA piles, including the change in the bearing capacity and load transfer. Brown and Powell [6] performed rapid load testing and static testing on precast, driven concrete piles and cast in situ CFA piles installed in high plasticity London Clay. Similarly, a comparison of two Osterberg's cell load tests (OLTs) and three conventional load tests (COLTs) in the same subsoil conditions on CFA piles was monitored during construction stages by Russo [7]. Liu et al. [8] conducted full-scale field 
load tests to study the differences in the bearing capacity and deformation properties between soil displacement screw (SDS) piles and CFA piles. Gavin et al. [9] discovered that the average shear resistance of CFA piles is greater and the base resistance is smaller than that of the pile driven in Dublin Boulder Clay. Seward et al. [10] adopted a field test in a CFA pile to investigate the extent of the remolded zone, the changes caused by remolding, and the effect of the installation method.

In terms of numerical analysis, Józefiak et al. [11] established a calculation model of pile-soil systems with ABAQUS software, which fits well with the field static load test results of CFA piles. Zhussupbekov et al. [12] employed an advanced constitutive hardening soil model obtained by Plaxis software to compare the bearing capacities of various pile types. Wang et al. [13] discussed the influence of the length-diameter ratio and pile-soil modulus ratio on the bearing characteristics of CFA piles by ANSYS software.

In terms of model tests, Krasiński and Kusio [14] carried out model tests on group piles and single piles of screw displacement piles (SDPs) and CFA piles and discovered that the load-settlement characteristics were not significantly different in high-density sand. Liu et al. [15] examined the differences in the bearing mechanism between SDS piles and CFA piles through sand foundation model tests. Different pile-forming methods will produce different interactions between the pile foundation and the surrounding soil, thus affecting the bearing capacity of the pile, which is an important factor in the design of pile foundations [16].

During the CFA pile-driving operation, the lowering of the reinforcement cage into concrete over the last several meters is greatly affected by the rheological properties of the concrete. Vanhove and Djelal [17] developed a device to assess the capability of introducing reinforcement cages into plastic concrete. To assess the choice and construction of each structure and structural component from a sustainability-based perspective, Josa et al. [18] explored the different alternatives of CFA piles: length (10 and $20 \mathrm{~m}$ ), reinforcement (steel cage reinforcement and structural fibers), and aggregates (natural crushed aggregates and recycled aggregate concrete sourced from stationary and mobile recycling plants) based on experimentally verified mix designs. Polishchuk and Tarasov [3] proposed a method using data on the auger impressing force and the physicalmechanical characteristics of the soils around the shaft of the CFA pile to calculate the carrying capacities of the soils.

There are two main methods of pile formation in model tests, i.e., static piling method and preset method [19]. The former adopts the static load and presses the model piles into the soil, while the latter sets the premade piles in the designed position followed by clay filling, which differs from the pile-forming method utilized in this paper. Compared with these two methods of pile formation in model tests, the construction technology and pile formation process of CFA piles have a greater impact on the bearing deformation characteristics of a pile. To simulate the actual pile-forming process of CFA piles, self-designed pile-forming equipment is employed in a clay-sand double-layer foundation. The model test can accurately establish and control the boundary conditions and material properties, and it is highly targeted at an investigation of the interaction between the pile and soil and its bearing characteristics [20].

In the model test, we compared the pile-forming mechanism of the CFA pile with the bored pile, which is easier to achieve in the model test than in the field test, and the results of the model tests were obtained, including the soil stress change around the pile, axial force, lateral friction resistance, and end resistance ratio of the pile. The selection of materials for model tests is rather challenging without centrifuge machines. The roles of the model test and field test are complementary. For this reason, the bearing mechanism and bearing performance of CFA piles are measured by field tests.

\section{Model Test}

2.1. Model Tank Design and Ground Model Preparation. An iron model tank with dimensions of $0.8 \mathrm{~m}$ (length) $\times 0.6 \mathrm{~m}$ (width) $\times 1.0 \mathrm{~m}$ (height) was assembled, and the diameter of the model pile was $40 \mathrm{~mm}$. Considering the boundary effect of the model test, the shortest distance between the pile core and the edge of the model tank is 6 times the pile diameter. Thirtytwo drainage holes, each with a diameter of $10 \mathrm{~mm}$, exist on both sides of the model tank, facilitating the consolidation of the ground model after the completion of filling. Before filling, permeable material is applied to the inner wall of the model tank to prevent the soil from extruding from the hole during the process of consolidation. A rectangular iron bar with a width of $0.05 \mathrm{~m}$ and a length of $0.8 \mathrm{~m}$ is welded on both sides of the top of the model tank to fix the forming equipment of the upper pile. A double-layer, ground model is filled in the tank with a sand layer at the pile end and a clay layer around the pile. The sand layer is $30 \mathrm{~cm}$ thick and located at the bottom of the model tank. The sand layer is rolled and compacted layer by layer with $10 \mathrm{~cm}$ in each layer and then saturated with water. The physical and mechanical properties are shown in Table 1. The thickness of the clay layer on top of the sand layer is $65 \mathrm{~cm}$; it is evenly laid layer by layer according to each $5 \mathrm{~cm}$ layer and then prepressed and consolidated; the clay was extracted from a foundation pit in Fenghua District, Ningbo, China. The physical and mechanical properties of the clay are shown in Table 2.

In the table, $D_{50}$ is the median particle diameter, $d_{s}$ is the specific gravity of the soil particle, $C_{u}$ is the uniformity coefficient, $C_{c}$ is the coefficient of curvature, $e_{\max }$ is the maximum void ratio, and $e_{\min }$ is the minimum void ratio.

In the table, $w$ is the water content, $\rho$ is the density, $\gamma$ is the unit weight of soil, $w_{P}$ is the plastic limit, and $w_{L}$ is the liquid limit.

In practical engineering, the ground is a uniform semiinfinite body, and the size of the structure in the soil differs greatly from that of soil particles. For the reduced-scale model test, the inhomogeneity effect of soil particles will be amplified, and the influence of the material particle size effect should be considered. In this paper, the ratio of the model pile size to the particle size of soil or sand exceeds 40 , and the particle size effect is relatively small and can be disregarded in the model test $[21,22]$. 
TABle 1: Physical and mechanical properties of the sand.

\begin{tabular}{lccccc}
\hline$D_{50}(\mathrm{~mm})$ & $d_{s}$ & $C_{u}$ & $C_{c}$ & $e_{\max }$ & $e_{\min }$ \\
\hline 0.27 & 2.65 & 3.1 & 0.9 & 0.912 & 0.608 \\
\hline
\end{tabular}

TABLe 2: Physical and mechanical properties of the clay.

\begin{tabular}{lcccc}
\hline$w(\%)$ & $\rho\left(\mathrm{g} / \mathrm{cm}^{3}\right)$ & $\gamma\left(\mathrm{kN} / \mathrm{m}^{3}\right)$ & $w_{P}(\%)$ & $w_{L}(\%)$ \\
\hline 42.7 & 1.83 & 17.6 & 25.9 & 47.3 \\
\hline
\end{tabular}

2.2. Pile-Forming Equipment. To simulate the actual pileforming process of CFA piles and to analyze the influence of construction technology on the bearing deformation characteristics of piles, model pile-forming equipment, which is composed of a drilling system, power system, grouting system, and lifting system, as shown in Figure 1, is designed and assembled.

Based on the pile length, the pressure of the grouting system is controlled to be $100 \sim 200 \mathrm{kPa}$, and the drilling speed is calculated according to the following formula [23]:

$$
V=n \cdot l \cdot\left(1-\frac{d_{0}^{2}}{d^{2}}\right)
$$

where $n$ is the rate of revolution, $d$ is the overall diameter of the auger, $d_{0}$ is the outer diameter of the central hollow stem, and the pitch of the screw is 1 .

The operation process of pile-forming equipment is described as follows:

(1) The power system applies torque to equip the drilling system with a long auger pipe drill into the design depth of the ground model.

(2) The grouting system starts grouting under pressure through the hollow drill pipe, and the lifting system controls the lifting of the drill pipe.

(3) After grouting is completed, the polyvinyl chloride (PVC) pipe is inserted into the simulated steel cage, and the pile is maintained.

2.3. System of the Load and Measure. The system includes a pressure sensor, displacement gauge, and static strain gauge. The range of the pressure sensor is $0 \sim 10 \mathrm{kN}$, and that of the displacement gauge is $0 \sim 10 \mathrm{~mm}$. Hydraulic jacks are employed to perform static load tests on the model pile, and the range is $0 \sim 100 \mathrm{kN}$, as shown in Figure 2.

The selection of materials for model tests is rather challenging. The use of steel cages contributes to excessive strength of the model piles, which may impact the loading deformation during the experimental research. Due to the pile-forming mechanism of CFA piles, PVC pipes provide a relatively suitable place for strain gauges. Because the elasticity modulus of the PVC pipe and pile material are similar, their deformation under the load is also similar, so the error of strain measurement can be reduced. In addition, the outer surface of a PVC pipe is more suitable for placing strain gauges. Zhou et al. [24] adopted a PVC pipe to conduct strain measurements to analyze the axial force,

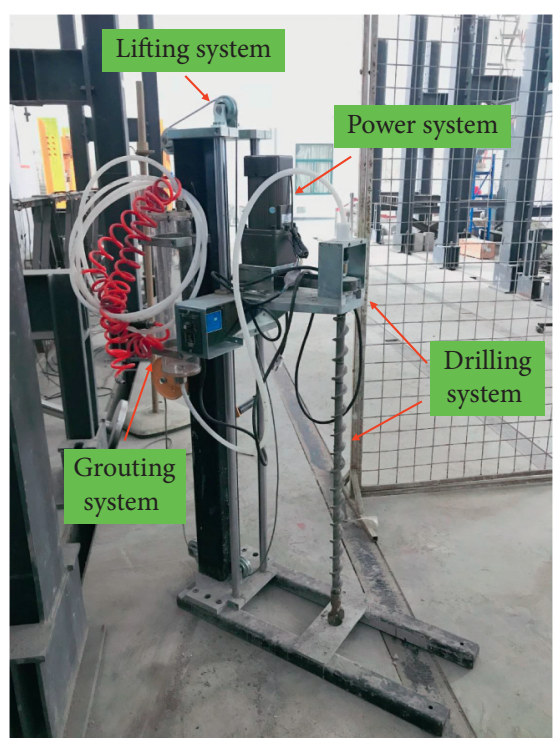

FIgURE 1: Photograph of the model pile-forming equipment.

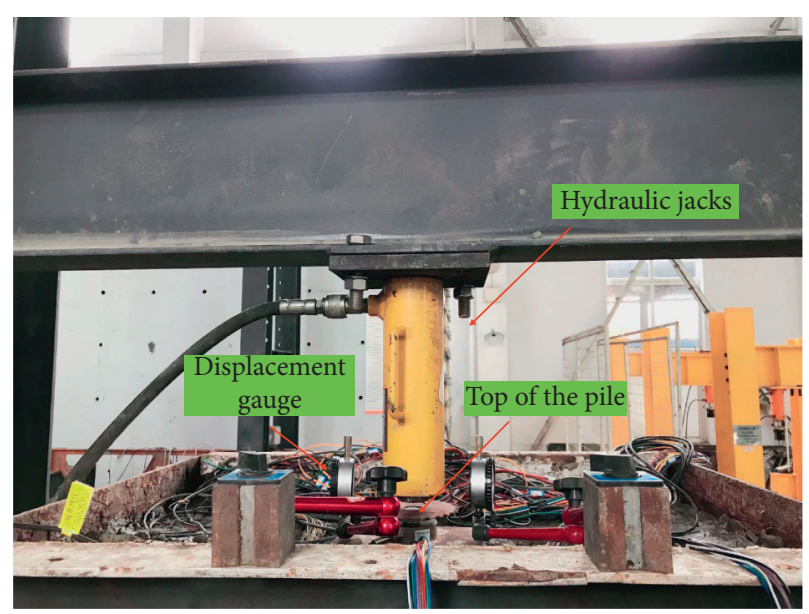

Figure 2: Loading system of the model test.

lateral friction resistance, and end resistance ratio of the pile during the static load test. For the model test process that simulates the real pile construction process, a hollow PVC pipe is utilized to simulate the reinforcement cage to measure the strain. The diameter of the PVC pipe is $20 \mathrm{~mm}$, and the wall thickness is $2 \mathrm{~mm}$. Six groups of strain measuring points are established on the outer surface according to the same distance, and each group is symmetrically set up with two resistance strain gauges. The wire is drawn from the pipe, as shown in Figure 3. Static strain gauges were used to read the changes in strain in different parts of the pile during the static load test.

2.4. Model Test Program. To study the pile-forming mechanism and bearing deformation characteristics of CFA piles, the control group of bored piles was established for analysis. The results included the change in the soil stress around the pile, axial force, lateral friction resistance of the pile, and end resistance ratio. The size parameters of the two types of piles 


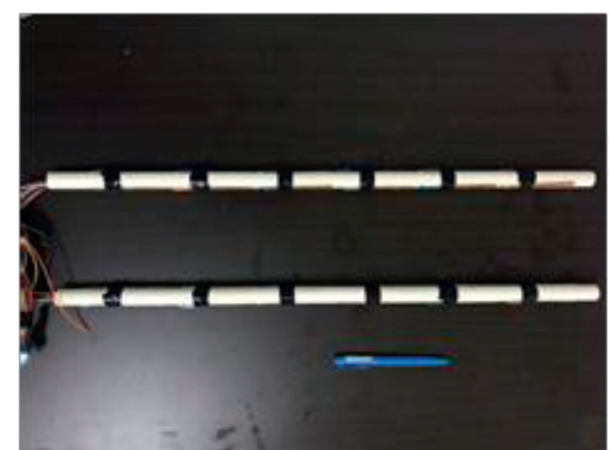

FIgURE 3: PVC pipe for simulating the steel cage.

are listed as follows: the pile diameter is $40 \mathrm{~mm}$; the length is $600 \mathrm{~mm}$; and the length-diameter ratio is 15.

To ensure that the conditions of the two types of piles are consistent in the comparison test, the CFA pile and bored pile are formed in the same ground model, and the pile ends are embedded into the sand layer at a depth 0.1 times the pile diameter. Earth pressure cells with a measuring range of $0 \sim 50 \mathrm{kPa}$, which are buried at different depths in the soil around the pile at a distance twice the pile diameter from the pile center, are utilized. The influence of construction technology and the piling process on the soil stress around the pile is then obtained. A pore water pressure gauge is embedded at the same distance on the other side of the pile to obtain the variation in pore water pressure in the ground model. An earth pressure cell with a measuring range of $0 \sim 400 \mathrm{kPa}$ is preembedded $2 \mathrm{~cm}$ below the pile end, which is selected to measure the change in the pile end resistance during the static load test, and a pressure sensor is placed on the pile top. The pile position and sensor arrangement in the model tank are shown in Figure 4.

R42.5 ordinary Portland cement was selected to prepare cement slurry with a water-cement ratio of $0.8: 1$. When the ground model was consolidated in the model tank, two types of model piles were constructed:

\section{(1) CFA pile}

The drill pipe in the drilling system is equipped with a one-way cock. After drilling to the design depth, the lifting system pulls out the drill pipe. Simultaneously, the grouting system is used to press the cement slurry through the hollow drill pipe to fill the pile hole. Immediately after the drilling machine was removed from the surface of the ground model, a PVC strain measuring pipe was inserted to maintain the pile.

(2) Bored pile

The soil sampler is applied to vertically extract soil at the predetermined pile position to form a pile hole, and then a PVC strain measuring pipe is inserted. Cement slurry is poured, and the pile is maintained.

In the initial stage of setting the cement slurry, the pile heads of the two kinds of model piles need to be treated with replenished slurry measures. Next, the whole pile was cured for 28 days, and then the static load test on a single pile was performed.

\section{Analysis of the Results}

3.1. Soil Stresses around the Pile. The variations in the soil stresses around the CFA pile and bored pile are shown in Figure 5. The relative pressure is defined as follows: the value of the pressure sensor buried in the ground model before piling is the zero point, a positive value of the soil pressure represents compression, a negative value of the soil pressure represents unloading, and the negative value of the pore water pressure is the decreasing value of the pore water pressure.

In the early drilling stage of the CFA pile, the soil around the pile will have a certain squeezing effect, which will increase the compaction and radial earth pressure of the soil around the pile. With continuous deepening of the drill pipe, the dregs in the borehole are discharged by the spiral blade, and the soil around the pile begins to exhibit an unloading effect. In the process of continuous pipe pulling up/grouting, the pressure of grouting can relieve the peak negative pressure caused by unloading and gradually stabilize it. The bored pile is composed of a soil sampler, so the soil around the pile is in a continuous unloading state, that is, hole wall stress relief and lateral relaxation deformation. The soil pressure around the two types of piles decreases with an increase in depth during the process of pile formation, while the negative pressure caused by unloading increases with an increase in depth. However, compared with the bored pile, the CFA pile will have a squeezing effect on the soil in the early drilling stage. After grouting, the negative pressure caused by unloading was reduced by $76 \%$ on average, and the dissipation effect of pore water pressure increased by $110 \%$.

3.2. Load-Settlement Curves. The load-settlement curves of the CFA pile and bored pile are shown in Figure 6.

The load-settlement curves of the two types of piles are consistent at the initial stage, and there is an obvious inflection point and a steep drop when the pile is damaged. When the load gradually increases, the slope of the loadsettlement curve of the bored pile increases, while the curve of the CFA pile remains flat until it becomes unstable. The amount of settlement of the CFA pile under different loads is smaller than that of the bored pile. The total settlement of the CFA pile is $3.3 \mathrm{~mm}$, which is $40.5 \%$ lower than the total settlement of the bored pile of $5.55 \mathrm{~mm}$.

According to the Technical Code for Testing of Building Foundation Piles (JGJ 106-2014) in China, the ultimate bearing capacity can take the load value corresponding to the point where an obvious sharp fall commences based on the sharp falling type $Q-s$ curve or can take the load value at the previous level of the position where the tail of the $s$-lgt curve exhibits an obvious downward bend. In this model test, the $Q-s$ curves represent the sharp falling type under $2400 \mathrm{~N}$ and $1650 \mathrm{~N}$ for the CFA pile and bored pile, respectively. The ultimate bearing capacity of the CFA pile is $2250 \mathrm{~N}$, which is $50 \%$ higher than that of the bored pile $(1500 \mathrm{~N})$. This analysis indicates that the CFA pile has a better deformation and bearing capacity than the bored pile due to their different pile-forming mechanisms. 


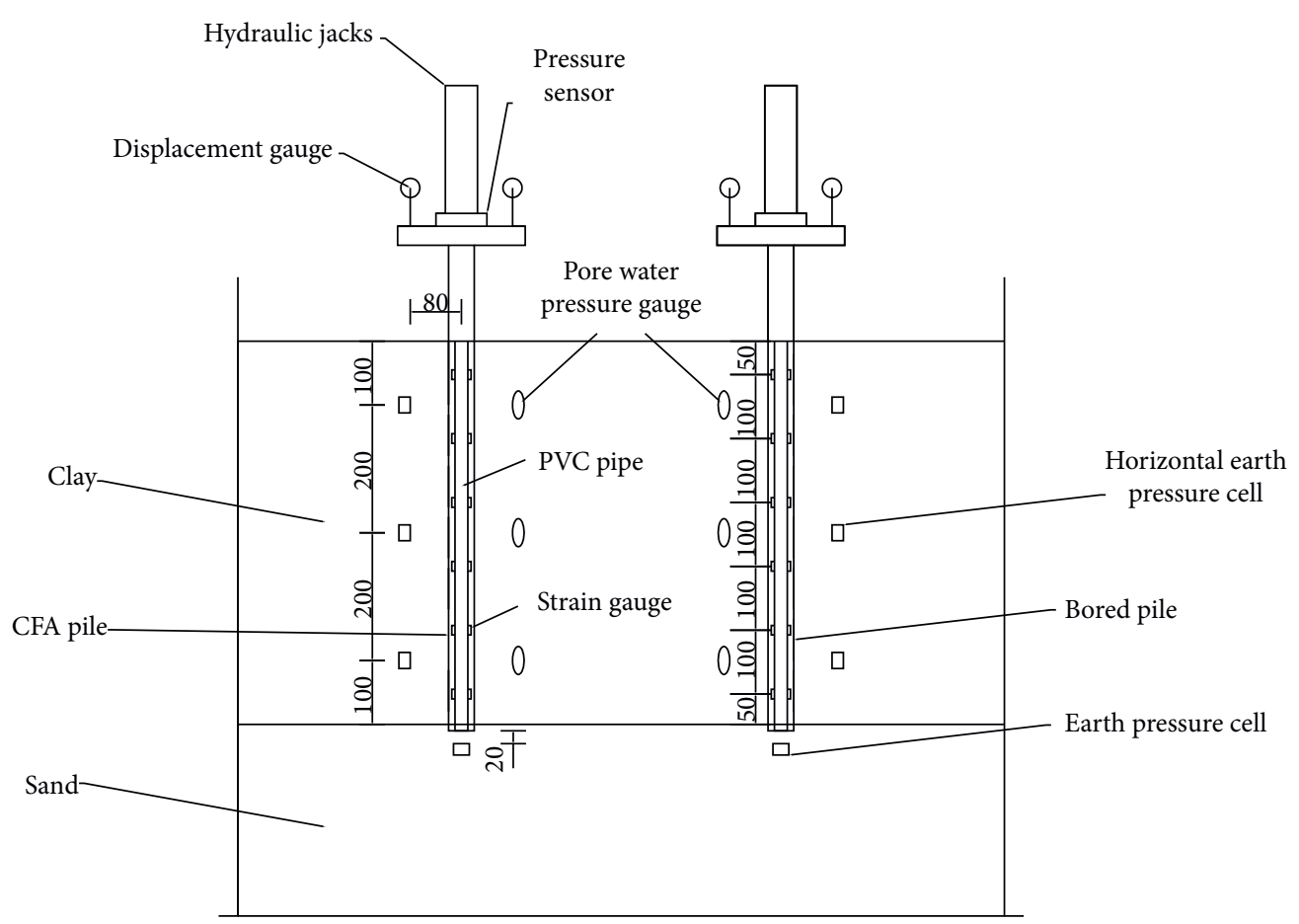

FIGURE 4: Section layout drawing of piles and sensors.

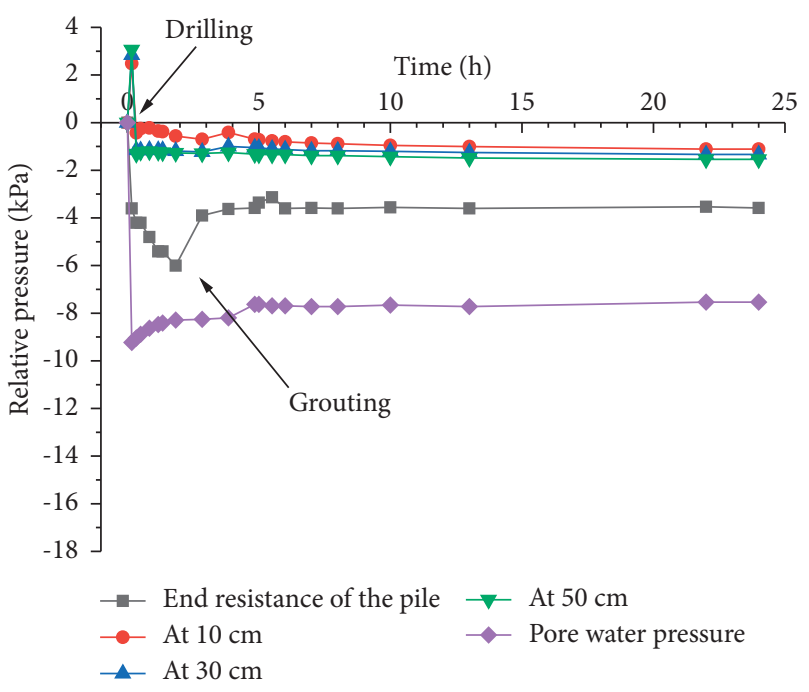

(a)

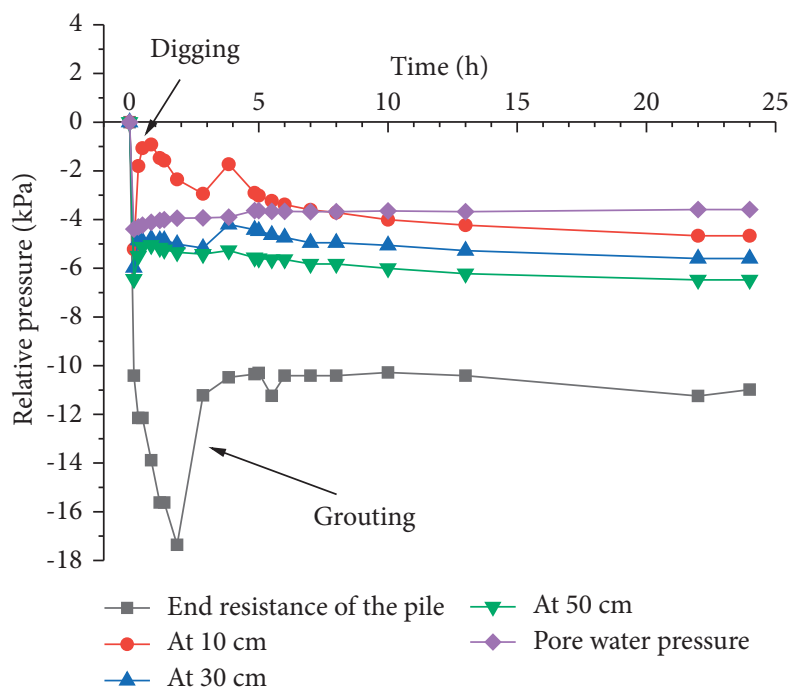

(b)

FIgURE 5: Variation in the stresses around the pile: (a) CFA pile; (b) bored pile.

3.3. Axial Force of the Pile. The axial force distribution of the piles is shown in Figure 7.

The axial force of the pile increases with an increase in load. As the pile body sinks and lateral friction resistance is generated on the pile side, the axial forces of the two pile types gradually decrease from the pile top to the pile end. The decreasing rate of the axial force on the upper pile body is larger than that on the lower pile body. Pile end resistance begins to gradually take effect. Compared with the bored pile, the axial force distribution curve of the CFA pile is gentler, and the axial load easily transfers along the depth direction. The results show that the CFA pile improves the pile-soil interface in the pile-forming mechanism.

3.4. Lateral Friction Resistance of the Pile. The lateral friction resistance of the piles is shown in Figure 8.

With an increase in the pile top load, the lateral friction resistance of the pile gradually develops along the direction of the depth. The upper pile body is larger than the lower pile body. At the initial stage of loading, the peak lateral friction 


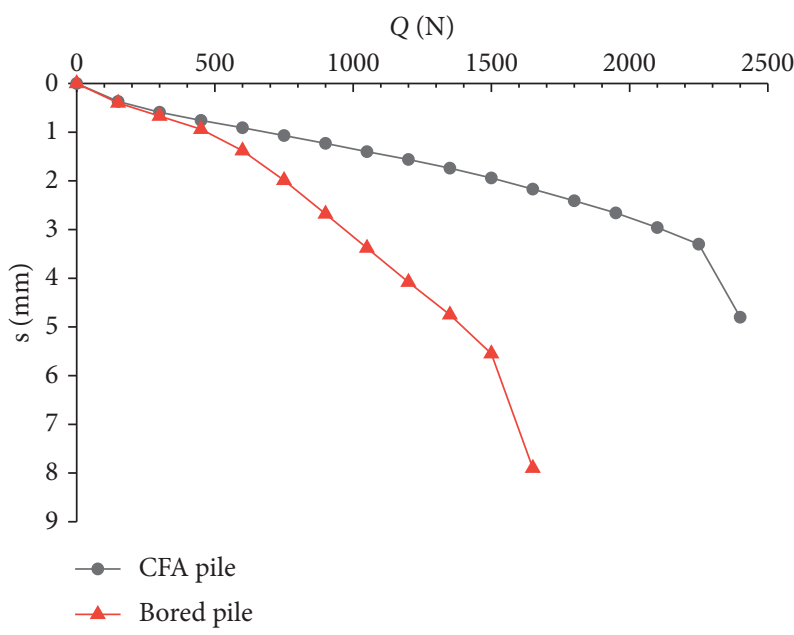

Figure 6: Load-settlement curves of the model piles.

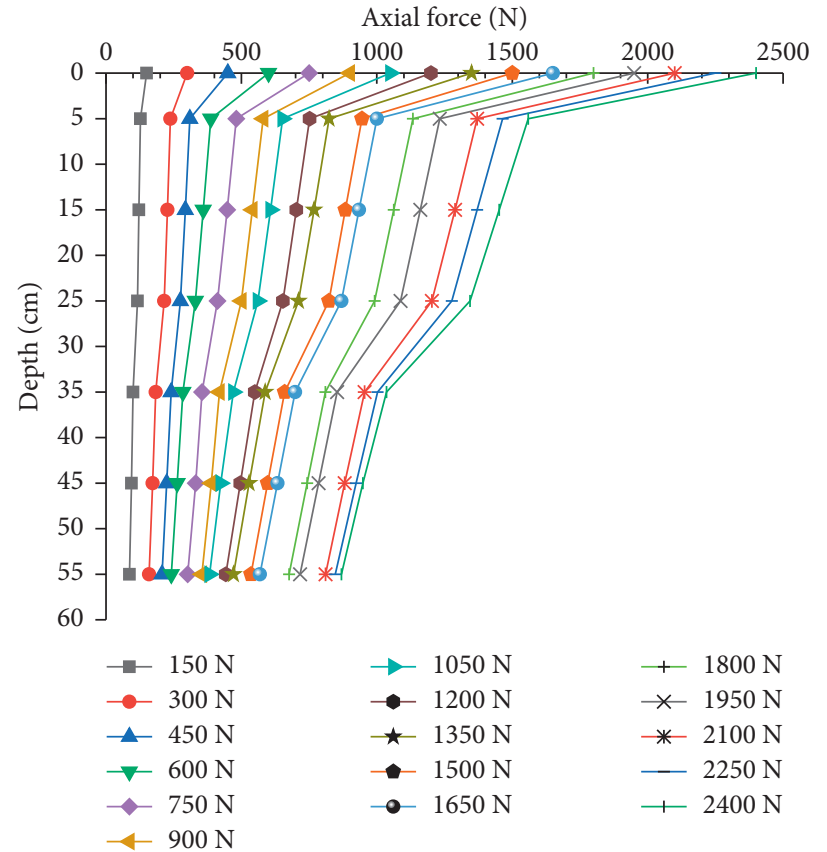

(a)

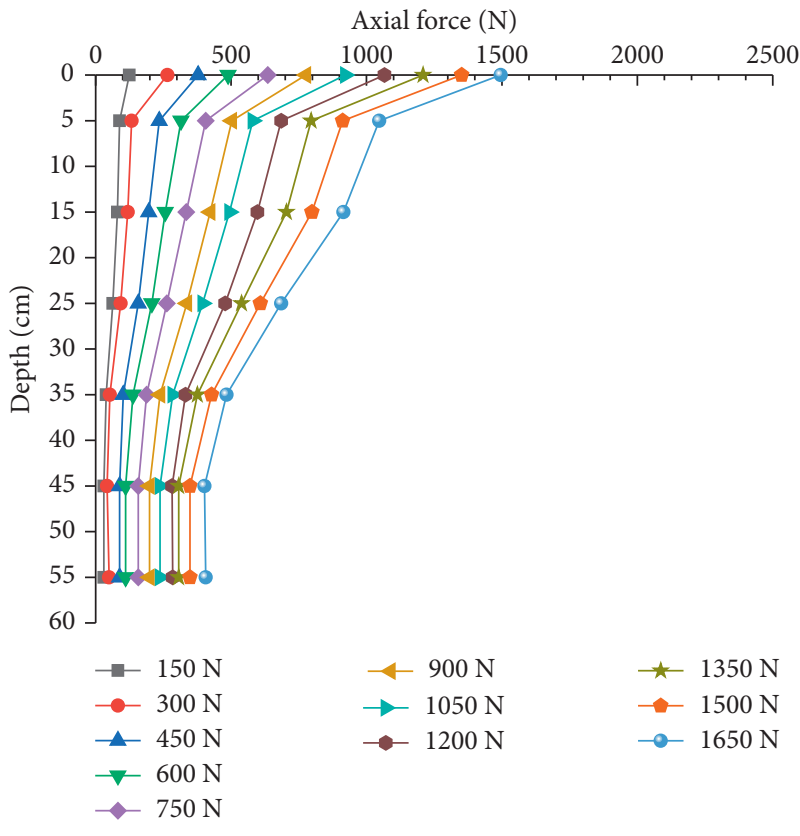

(b)

Figure 7: Axial force distribution diagram of the pile: (a) CFA pile; (b) bored pile.

resistance of the lower pile was not obvious, and the compressive deformation of the pile was mainly concentrated in the upper pile. With a gradual increase in load, the lateral friction resistance of the lower pile began to develop gradually, and the peak value of the curve of the lateral friction resistance of the pile became more obvious. At the first peak, the lateral friction resistance is the greatest.

The peak value and depth of the lateral friction resistance of the CFA pile and bored pile are different. The first peak value of the CFA pile was in the range of $0 \sim 10 \mathrm{~cm}$ from the top of the pile, while the first peak value of the bored pile was in the range of $5 \sim 15 \mathrm{~cm}$ from the top of the pile. Under the same load of $1650 \mathrm{~N}$, the peak lateral friction resistance of the bored pile was only $34.5 \%$ of that of the CFA pile.
3.5. End Resistance Ratio. The pile end resistance ratio is the ratio of the pile end resistance to the pile top load, namely, $Q_{b} / Q$. The pile end resistance ratio curves are shown in Figure 9.

The pile end resistance and lateral friction resistance of the two types of piles are developed asynchronously, and the pile end resistance increases with an increase in the pile top load. The pile end resistance ratio exhibits continuous growth with an increase in load. The pile end resistance increases faster than the pile lateral friction resistance, and the pile lateral friction resistance has a more sufficient role when the load is lower.

The lateral friction resistance of the CFA pile is more fully developed, especially in the case of a high load. Under 


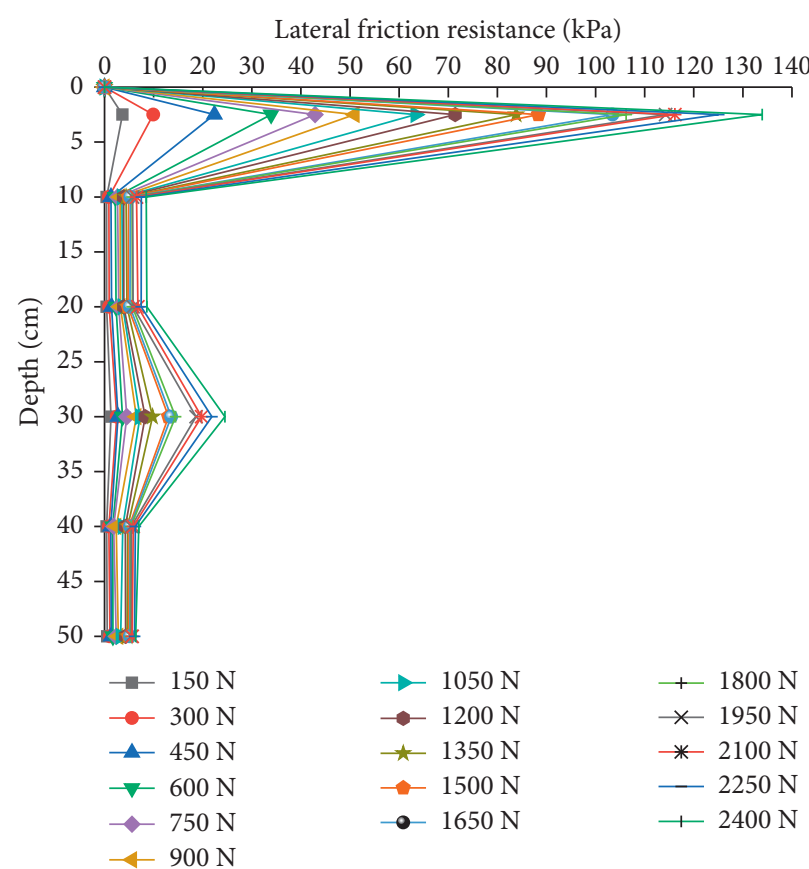

(a)

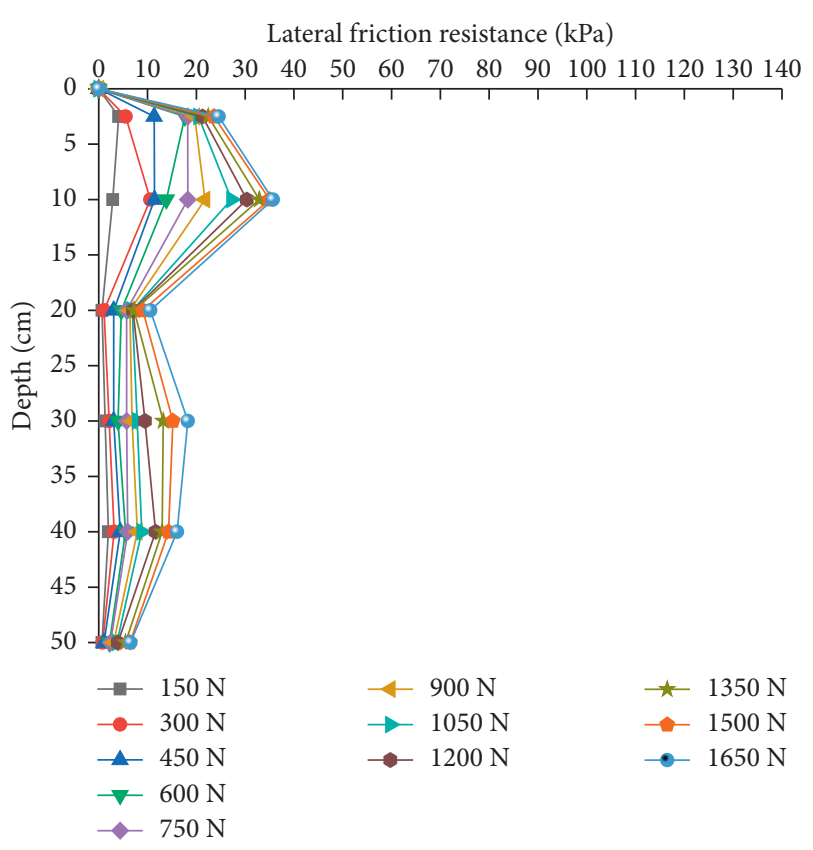

(b)

Figure 8: Distribution diagram of the lateral friction resistance of the pile: (a) CFA pile; (b) bored pile.

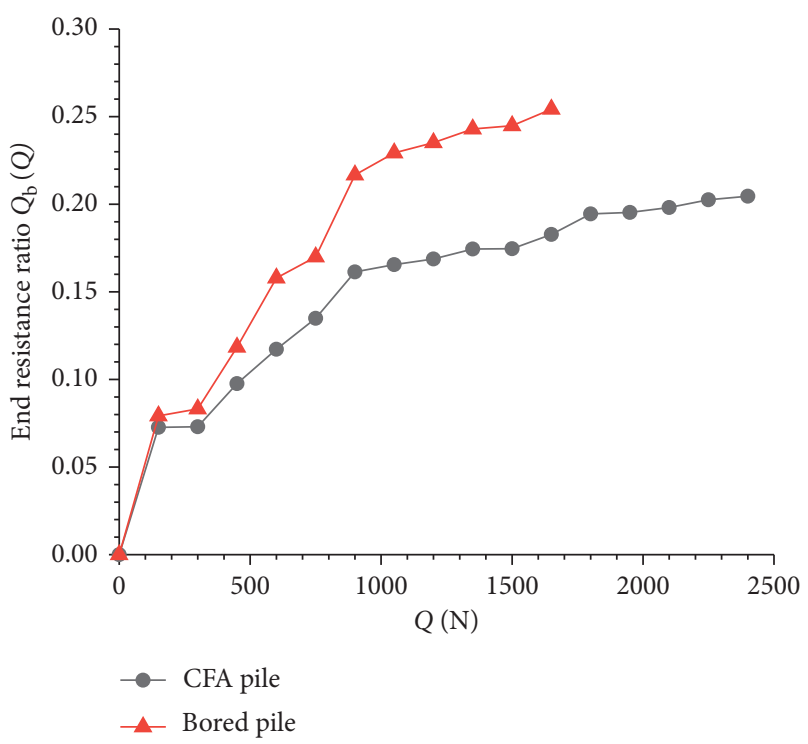

Figure 9: Curves of the end resistance ratio for the two types of piles.

the low load of $750 \mathrm{~N}$ on the pile top, the pile end resistance ratio of the CFA pile is $13.5 \%$, while the pile end resistance ratio of the bored pile is $17.0 \%$. Under the high load of $1500 \mathrm{~N}$ on the pile top, the pile end resistance ratio of the CFA pile is $17.5 \%$, while that of the bored pile is $24.4 \%$. The end resistance ratio of the CFA pile is smaller than that of the bored pile under the same load, which means that the soil surrounding the CFA pile bears a higher upper load than that surrounding the bored pile. When the pile is unstable, the pile end resistance ratio of the CFA pile is $20.5 \%$, and the pile end resistance ratio of the bored pile is $25.4 \%$. The higher the load on the pile top is, the greater the difference in the pile end resistance ratio between the two pile types.

\section{Pile-Forming Mechanism and Engineering Case Analysis}

4.1. Pile-Forming Mechanism. The pile-forming mechanism of CFA piles includes the soil improvement effect around the pile and the diameter expansion effect during the drilling and grouting process. After the simulation of the pileforming and static load test, the pile body was excavated and removed, as shown in Figure 10.

Compared with the bored pile, the CFA pile will produce a certain squeezing effect on the soil around the pile in the initial drilling stage due to the rotation of the screw, which compacts the soil on the side of the pile and increases the radial soil pressure. The grouting pressure weakens the unloading effect caused by the discharge of dregs. A slight thread and changes in the soil stress state as well as a diameter expansion effect are observed. Compared with the pile diameter of $4.3 \mathrm{~cm}$ in the middle of the bored pile, the pile diameter in the middle of the CFA pile increased by $19 \%$ to $5.1 \mathrm{~cm}$.

Simultaneously, a soil improvement effect is observed. The cement slurry extrusion penetrates into the soil around the pile, and the soil around the pile forms the transformation zone. The physical and mechanical parameters $c, \varphi$ and the lateral earth pressure coefficient deserve further investigation for potential improvement. The soil around the pile becomes more compact. A pile-soil complex, which increases the contact area between the pile body and the soil 


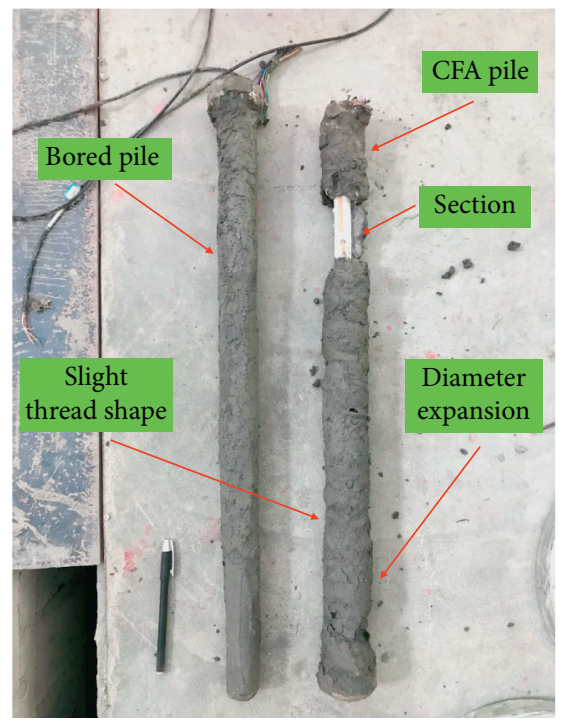

Figure 10: Photograph of the excavated pile body in the model test.

Table 3: Type and physical parameters of the design test piles.

\begin{tabular}{lcc}
\hline Type & Diameter $(\mathrm{mm})$ & Length $(\mathrm{m})$ \\
\hline CFA pile & 800 & 14.9 \\
Manual digging pile & 800 & 15.2 \\
CFA pile & 700 & 18.9 \\
\hline
\end{tabular}

TABLE 4: Main formation conditions and physical and mechanical parameters.

\begin{tabular}{|c|c|c|c|c|c|c|c|}
\hline Layer & Soil type & Thickness (m) & $w(\%)$ & $\gamma\left(\mathrm{kN} / \mathrm{m}^{3}\right)$ & $c(\mathrm{kPa})$ & $\varphi\left(^{\circ}\right)$ & $E_{s}(\mathrm{MPa})$ \\
\hline 1 & Miscellaneous fill & 2.0 & 28.0 & 19.6 & 6.0 & 10.0 & 6.10 \\
\hline 2 & Silty clay & 2.7 & 27.7 & 19.2 & 36.3 & 11.4 & 5.89 \\
\hline 3 & Mucky silty clay & 2.2 & 45.2 & 18.3 & 9.7 & 3.5 & 3.31 \\
\hline 4 & Silty clay & 1.2 & 32.3 & 18.8 & 13.7 & 5.3 & 4.55 \\
\hline 5 & Pebble & 1.4 & 18.9 & 20.8 & 34.7 & 5.3 & 13.15 \\
\hline 6 & Pebble with clay soil & 2.9 & 24.0 & 20.0 & 10.0 & 25.0 & 7.48 \\
\hline 7 & Silty clay & 2.2 & 30.6 & 19.5 & 34.3 & 12.2 & 6.27 \\
\hline 8 & Fully weathered sandstone & 17.7 & 18.3 & 20.7 & 33.0 & 18.5 & 10.00 \\
\hline
\end{tabular}

around the pile, is formed. As indicated by the pile end resistance ratio data, compared with the bored pile, the total lateral friction resistance of the CFA pile increased by $4.2 \%$ at a low load $(150 \mathrm{~N})$ and increased by $9.1 \%$ at a high load $(1500 \mathrm{~N})$.

4.2. Engineering Case Analysis. The static load test results of a project in Fenghua District of Ningbo are analyzed. The pile type and parameters of the designed test pile are shown in Table 3, and the main formation conditions and physical and mechanical parameters are shown in Table 4.

The load-settlement curves of the field test piles are shown in Figure 11.

Under the condition that the pile diameters are equivalent, the load-settlement curves of the CFA pile and manual digging pile under medium and low loads $(0 \sim 1500 \mathrm{kN})$ are consistent, and an obvious inflection point and steep drop form when the pile is damaged. When the load increases, the load-settlement curve of the CFA pile is relatively gentle until it becomes unstable compared with the manual digging pile. Under a high load, the lateral friction resistance of the CFA pile is more fully developed. The ultimate bearing capacity of the CFA pile is $4550 \mathrm{kN}$, which is $14.9 \%$ higher than that of the manual digging pile. The total settlement of the CFA pile is $26.4 \mathrm{~mm}$, which is $19.0 \%$ lower than that of the manual digging pile. The results are consistent with the model test results.

Under the conditions of different pile diameters, the load-settlement curve of the CFA pile is similar to that of the manual digging pile under medium and low loads $(0 \sim 2000 \mathrm{kN})$, and the bearing performance of the CFA pile with a small pile diameter is similar to that of the manual digging pile with a large pile diameter. CFA piles with small pile diameters were not loaded to failure, and the slope of the load-settlement curve increased with an increase in load. The curve gradually changed from manual digging piles with large pile diameters, and the influence of the pile diameter gradually became prominent under high loads. 


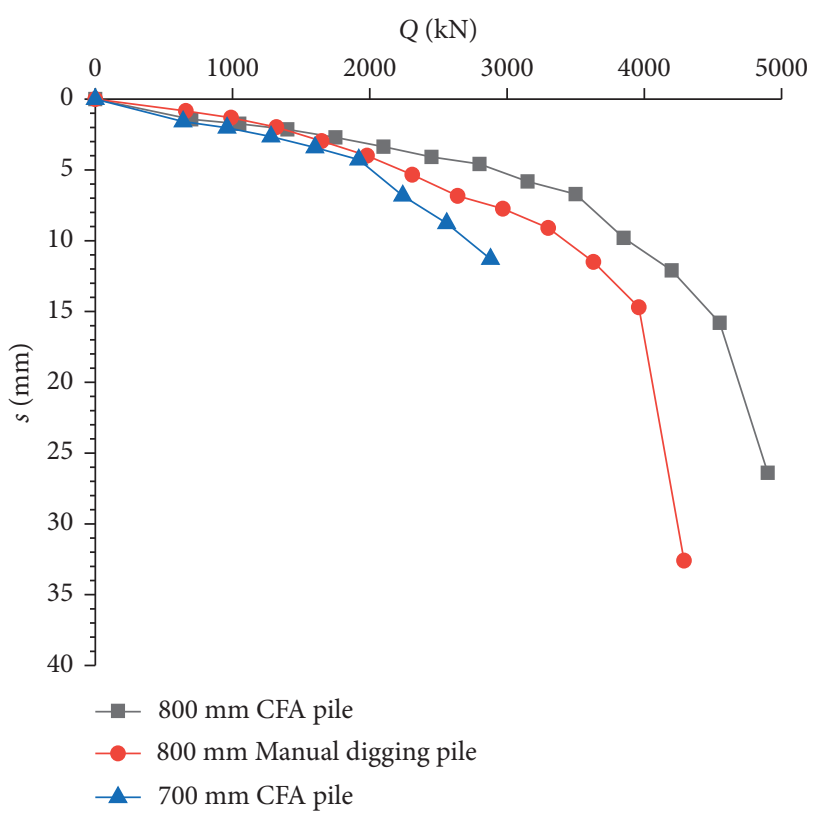

Figure 11: Load-settlement curves of the test piles.

\section{Conclusions}

In this paper, the pile-forming technology and process of site construction are simulated by homemade pile-forming equipment, and the geological situation of the site is simulated by a clay-sand double-layer ground model. Comparative model tests were performed on CFA piles and bored piles, and the pile-forming mechanism and bearing deformation characteristics of the CFA pile were further analyzed based on the static load test results of the field engineering test pile.

In the model test, the pile-forming mechanism of the CFA pile is compared with that of the bored pile, which is easier to achieve in the laboratory than in the field. The pileforming mechanism mainly includes the soil improvement effect around the pile and the diameter expansion effect. Compared with the values associated with the bored pile, the CFA pile has a diameter enlargement of 19\%, and the total lateral friction resistance is increased by $4 \% \sim 10 \%$. Therefore, the lateral friction resistance can be more fully developed, the settlement of the pile is smaller, the bearing capacity is larger, and in general the bearing capacity is better.

In the field pile test, under the condition that the pile diameters are the same, the load-settlement curves of the two kinds of piles at the initial stage of loading are relatively consistent. Under a high load, the lateral friction resistance of the CFA pile is more fully developed. When the load increases, the load-settlement curve of the CFA pile is relatively gentle until it becomes unstable. With different pile diameters, the slope of the load-settlement curve of the CFA pile increases with an increase in load, and the curve gradually differs from that of the manual digging pile with large pile diameters. The influence of pile diameters gradually becomes prominent under high loads.

\section{Data Availability}

The data used to support the findings of this study are included within the article.

\section{Conflicts of Interest}

The authors declare that they have no conflicts of interest.

\section{Acknowledgments}

This research was supported by the National Natural Science Foundation of China (No. 51378469); the Natural Science Foundation in Zhejiang Province, China (Nos. LZ20E080001 and LQ19E080009); the Natural Science Foundation in Fujian Province, China (No. 2020J01400); the Program for New Century Excellent Talents in Fujian Province University, China; and the Engineering Research Center of Prevention and Control of Geological Disasters in Northern Fujian, Fujian Province University, China (WYERC 2020-3).

\section{References}

[1] D. A. Brown, "Practical considerations in the selection and use of continuous flight auger and drilled displacement piles," in Proceedings of the Advances in Designing and Testing Deep Foundations: In Memory of Michael W. O’Neill, pp. 251-261, Austin, Texas,USA, January 2005.

[2] S. Bersan, O. Bergamo, L. Palmieri, L. Schenato, and P. Simonini, "Distributed strain measurements in a CFA pile using high spatial resolution fibre optic sensors," Engineering Structures, vol. 160, pp. 554-565, 2018.

[3] A. I. Polishchuk and A. A. Tarasov, "CFA pile carrying capacity determination in weak clay soils for renovated-building foundations," Soil Mechanics and Foundation Engineering, vol. 54, no. 1, pp. 38-44, 2017.

[4] W. N. A. Elsamee, "New method for prediction pile capacity executed by continuous flight auger (CFA)," Engineering, vol. 5, no. 4, pp. 344-354, 2013.

[5] B. Liu, D. Zhang, and P. Xi, "Mechanical behaviors of SD and CFA piles using BOTDA-based fiber optic sensor system: a comparative field test study," Measurement, vol. 104, pp. 253-262, 2017.

[6] M. J. Brown and J. J. M. Powell, "Comparison of rapid load pile testing of driven and CFA piles installed in high OCR clay," Soils and Foundations, vol. 52, no. 6, pp. 1033-1042, 2012.

[7] G. Russo, "Experimental investigations and analysis on different pile load testing procedures," Acta Geotechnica, vol. 8, no. 1, pp. 17-31, 2013.

[8] Z. Liu, S. Yang, J. Lu, and Z.-Y. Li, "Full scale field load tests on bearing capacity of SDS pile and CFA pile," Chinese Journal of Geotechnical Engineering, vol. 32, no. S2, pp. 127-131, 2010.

[9] K. Gavin, D. Cadogan, and L. Twomey, "Axial resistance of CFA piles in Dublin boulder clay," Proceedings of the Institution of Civil Engineers - Geotechnical Engineering, vol. 161, no. 4, pp. 171-180, 2008.

[10] L. J. Seward, S. E. Stallebrass, and J. Skipper, "Remoulding of the mercia mudstone group around CFA pile shafts," The Quarterly Journal of Engineering Geology and Hydrogeology, vol. 46, no. 1, pp. 41-51, 2013. 
[11] K. Józefiak, A. Zbiciak, M. Maślakowski, and T. Piotrowski, "Numerical modelling and bearing capacity analysis of pile foundation," Procedia Engineering, vol. 111, pp. 356-363, 2015.

[12] A. Z. Zhussupbekov, J. Frankovská, J. Stacho et al., "Geotechnical and construction considerations of pile foundations in problematical soils," Japanese Geotechnical Society Special Publication, vol. 2, no. 79, pp. 2704-2709, 2016.

[13] X. Wang, M. Zhang, F. Liu, and L. Zhong, "Numerical simulation for pile-soil interaction of long-spiral-compactedconcrete pile," Journal of Wuhan University of Technology, vol. 28, no. 10, pp. 73-76, 2006.

[14] A. Krasiński and T. Kusio, "Comparative model tests of SDP and CFA pile groups in non-cohesive soil," Studia Geotechnica et Mechanica, vol. 36, no. 4, pp. 7-11, 2015.

[15] Z. Liu, J. Lu, Y. Zhang, and Z. Li, "Model test study of load deformation behavior of soil displacement screw pile in sand," Chinese Journal of Rock Mechanics and Engineering, vol. 30, no. 3, pp. 616-624, 2011.

[16] N. Duan, Y. P. Cheng, and J. W. Liu, "DEM analysis of pile installation effect: comparing a bored and a driven pile," Granular Matter, vol. 20, no. 3, p. 36, 2018.

[17] Y. Vanhove and C. Djelal, "Influence of rheological properties of concrete foundation on the implementation of continuous flight auger (CFA) piles," Materials and Structures, vol. 53, no. 5 , pp. $1-15,2020$.

[18] I. Josa, N. Tošić, S. Marinković, A. de la Fuente, and A. Aguado, "Sustainability-oriented multi-criteria analysis of different continuous flight auger piles," Sustainability, vol. 13, no. 14, p. 7552, 2021.

[19] C. Wang, "Some discussions of making method on indoor model pile," in Proceedings of the 7th Conference on Soil Mechanics and Foundation Engineering, pp. 437-441, China Architecture and Building Press, Mexico City, Mexico, 1994.

[20] Y. Zeng, W. Zhang, and N. Wang, "Reviews of state-of-art of modeling simulation on pile foundations," Rock and Soil Mechanics, vol. 24, no. S2, pp. 674-680, 2003.

[21] N. K. Ovesen, "The scaling law relationship-panel discussion," in Proceedings of the 7th European Conference on Soil Mechanics and Foundation Engineering, vol. 4, pp. 319-323, Brighton, UK, 1979.

[22] W. H. Craig, "Simulation of foundations for offshore structures using centrifuge modelling," in Developments in Soil Mechanics and Foundation Engineering: Model Studies, Applied Science Publishiers Ltd., London, UK, 1983.

[23] A. Mandolini, M. Ramondini, G. Russo, and C. Viggiani, "Full scale loading tests on instrumented CFA piles," in Proceedings of the Deep Foundations 2002: An International Perspective on Theory, Design, Construction, and Performance, pp. 10881097, Orlando, FL, USA, February 2002.

[24] J. Zhou, X. Gong, K. Wang, and R. Zhang, "Model test on load transfer mechanism of a static drill rooted nodular pile," Journal of Zhejiang University (Engineering Science), vol. 49, no. 3, pp. 531-537, 2015. 